\title{
Morphological spectrum of atherosclerotic lesions in a tertiary care Institute in Punjab
}

\author{
Rajiv Kumar Gupta ${ }^{1}$, RuchitaTyagi², Vikrampal Singh ${ }^{3}$, Samir Kapoor ${ }^{4}$, Gurmeet Singh ${ }^{5}$, \\ Sarju Ralhan ${ }^{6}$, Pavneet Kaur Selhi', Bhavna Garg ${ }^{8}$, Harpreet Kaur ${ }^{9}$, Neena Sood ${ }^{10}$, \\ Naved Aslam ${ }^{11}$, Gurpreet Singh Wander ${ }^{12}$ \\ Professor \& Head ${ }^{1}$, Associate Professor ${ }^{3}$, Assistant Professor ${ }^{4,5}$, Senior Consultant Cardiac Surgeon ${ }^{6,}$ Cardiothoracic \\ and Vascular surgery, Hero DMC Heart Institute, Ludhiana Assistant Professor ${ }^{2}$, Professor 7,8,9,10, Pathology, Dayanand \\ Medical College and Hospital, Ludhiana Professor ${ }^{11,}$ Professor and Head ${ }^{12}$. Cardiology, Hero DMC Heart Institute, \\ Ludhiana.
}

\section{A B S T R A C T}

Background: The incidence of coronary artery disease (CAD) has risen considerably in developing world due to industrialization, urbanisation and lifestyle changes, especially among Indians and South Asians. The onset of CAD has been seen to occur at an early age and the severity of the disease and mortality associated with CAD has also increased. The pathology of atherosclerosis needs to be re-evaluated to develop targeted therapy which can contain the disease process at the earliest stage. Aims and Objectives: Most of the morphological studies on atherosclerosis have been done on autopsy cases. In this study, we have analysed the morphological spectrum of atherosclerotic lesions in live patients. Materials and Methods: We retrospectively analysed the histopathology slides of 85 cases whose endarterectomy plaques were received in the Department of Pathology over a period of three and half years (January 2014 to June 2017) and classified the lesions according to Modified American Heart Association classification of atherosclerosis. Results : The average age of patients was 60 years and male to female ratio of 4.3:1. Left anterior descending artery was the commonest vessel involved (52.4\%). Majority of the cases had fibrocalcific plaques, followed by fibrous cap atheroma and calcified nodules. Conclusion: Coronary artery plaques were found even in patients less than 40 years old. Aggressive lipid defense therapy needs to be the cornerstone of management of CAD.

Key words: Atherosclerosis; Coronary artery; Risk factors; Plaque
Access this article online

Website:

http://nepjol.info/index.php/AJMS DOI: 10.3126/ajms.v10i1.21664 E-ISSN: 2091-0576 P-ISSN: 2467-9100

\section{INTRODUCTION}

Coronary artery disease (CAD) is a type of cardiovascular disease (CVD). The incidence of CAD has risen considerably in developing world due to industrialization, urbanisation, sedentary lifestyle, increased stress and poor dietary habits. CVD accounted for $33.2 \%$ of total and $45 \%$ of adult deaths in 2015. ${ }^{1}$ Atherosclerosis is responsible for CAD and CVD. Keeping these facts in mind, it is the need of the hour to take a comprehensive relook at the pathology of atherosclerosis in order to develop targeted therapy which can contain the disease process at the earliest stage possible.
Most of the studies on morphology of atherosclerotic lesions have been done on autopsy cases. We have analysed the morphological spectrum of atherosclerotic lesions in live patients who underwent endarterectomy during revascularization.

\section{MATERIAL AND METHODS}

This was a retrospective analysis of histopathology slides of 85 cases whose endarterectomy plaques were received in the Department of Pathology of our tertiary care institute over a period of three and half years (January 2014 to June 2017). The clinical details of the patients were retrieved from the 
requisition forms. All the patients had undergone coronary artery bypass grafting for stenosis of coronary arteries caused by atherosclerosis. The excised specimens of involved coronary arteries were received in the Department of Pathology. The specimens were routinely processed and stained with Hematoxylin and Eosin (H\&E) stain. Special stains like Massons Trichrome were performed wherever required to assess the fibrous component in plaques. The slides of all these cases were reviewed and lesions classified according to Modified American Heart Association classification of atherosclerosis (Table 1).

\section{RESULTS}

We studied 85 cases where histopathological examination of coronary artery plaques was done.

The ages of the patients ranged from $37-83$ years, with average age of 60 years. Most of the cases were in age range $51-70$ years. (Table 2 ) There was stark male predominance with male to female ratio of 4.3:1.

45 cases (52.38\%) had lesions in left anterior descending artery, 26 cases $(30.95 \%)$ had lesions in right coronary artery and 14 cases (16.67\%) had lesions in left circumflex artery. (Table 3)

The commonest lesion was fibrocalcific plaque, seen in 58 cases. (Figure 1) The plaque had necrotic core which showed areas of calcificationsurrounded by foamy macrophages and lymphocytes, with surrounding fibrotic areas.

Fibrous cap atheroma was noted in 15 cases (Figure 2). The plaque had foci of necrosis, areas of haemorrhage and fibrin deposits. The plaque was rimmed by a fibrous cap, which was infiltrated by lymphocytes and foamy macrophages.

Four cases had calcified nodules in which fibrocalcific plaque showed large areas of calcification over it. The underlying tunica media had cholesterol clefts and foamy macrophages, surrounded by collagen rich fibrous cap.

Plaque rupture (Figure 3) was seen in two cases. There was infiltration of foamy macrophages and lymphocytes in a ruptured fibrous cap which was communicating with necrotic core of underlying plaque.

Two cases displayed pathological thickening of intima (Figure 4). The arterial wall showed thickening due to proliferation of smooth muscle cells with cholesterol clefts. There was no plaque formation or necrosis.

There were also two cases each of non - atherosclerotic intimal xanthoma and Non - atherosclerotic intimal thickeningwas seen in two cases (Figure 5). The arterial wall showed thickening due to proliferation of smooth muscle cells. There was no lipid accumulation or cholesterol clefts or inflammatory cells.

\begin{tabular}{|c|c|c|}
\hline & Description & Thrombosis \\
\hline \multicolumn{3}{|l|}{ Non-atherosclerotic lesions } \\
\hline Intimal thickening & $\begin{array}{l}\text { The normal accumulation of Smooth Muscle } \\
\text { Cells (SMCs) in the intima in the absence of lipid or } \\
\text { macrophage foam cells }\end{array}$ & Absent \\
\hline \multicolumn{3}{|l|}{ Progressive atherosclerotic lesions } \\
\hline Pathological intimal thickening & $\begin{array}{l}\text { SMCs in a proteoglycan-rich matrix with areas of } \\
\text { extracellular lipid accumulation without necrosis }\end{array}$ & Absent \\
\hline Erosion & Luminal thrombosis; plaque same as above & $\begin{array}{l}\text { Thrombus mostly mural and } \\
\text { infrequently occlusive }\end{array}$ \\
\hline Erosion & $\begin{array}{l}\text { Luminal thrombosis; plaque same as above; no } \\
\text { communication of thrombus with necrotic core }\end{array}$ & $\begin{array}{l}\text { Thrombus mostly mural and } \\
\text { infrequently occlusive }\end{array}$ \\
\hline Thin fibrous cap atheroma & $\begin{array}{l}\text { A thin fibrous cap infiltrated by macrophages and } \\
\text { lymphocytes with rare SMCs and an underlying necrotic } \\
\text { core }\end{array}$ & $\begin{array}{l}\text { Absent; may contain intraplaque } \\
\text { hemorrhage/fibrin }\end{array}$ \\
\hline Plaque rupture & $\begin{array}{l}\text { Fibroatheroma with cap disruption; luminal thrombus } \\
\text { communicates with the underlying necrotic core }\end{array}$ & Thrombus usually occlusive \\
\hline Calcified nodule & $\begin{array}{l}\text { Eruptive nodular calcification with underlying fibrocalcific } \\
\text { plaque }\end{array}$ & Thrombus usually nonocclusive \\
\hline Fibrocalcific plaque & $\begin{array}{l}\text { Collagen-rich plaque with significant stenosis } \\
\text { usually contains large areas of calcification with few } \\
\text { inflammatory cells; a necrotic core may be present. }\end{array}$ & Absent \\
\hline
\end{tabular}




\begin{tabular}{|c|c|c|c|c|c|c|c|c|}
\hline $\begin{array}{l}\text { Age } \\
\text { range (yrs) }\end{array}$ & $\begin{array}{l}\text { Non atherosclerotic } \\
\text { intimal thickening }\end{array}$ & $\begin{array}{c}\text { Non atherosclerotic } \\
\text { xanthoma }\end{array}$ & $\begin{array}{c}\text { Pathological } \\
\text { intimal thickening }\end{array}$ & $\begin{array}{l}\text { Fibrous cap } \\
\text { atheroma }\end{array}$ & $\begin{array}{l}\text { Plaque } \\
\text { rupture }\end{array}$ & $\begin{array}{l}\text { Calcified } \\
\text { nodule }\end{array}$ & $\begin{array}{c}\text { Fibrocalcific } \\
\text { plaque }\end{array}$ & Tota \\
\hline $31-40$ & 0 & 0 & 0 & 0 & 0 & 0 & 2 & 2 \\
\hline $41-50$ & 0 & 2 & 2 & 4 & 0 & 0 & 10 & 18 \\
\hline $51-60$ & 0 & 0 & 0 & 3 & 0 & 2 & 22 & 27 \\
\hline $61-70$ & 2 & 0 & 0 & 6 & 0 & 2 & 16 & 26 \\
\hline $71-80$ & 0 & 0 & 0 & 2 & 0 & 0 & 8 & 10 \\
\hline $81-90$ & 0 & 0 & 0 & 0 & 2 & 0 & 0 & 2 \\
\hline Total & 2 & 2 & 2 & 15 & 2 & 4 & 58 & 85 \\
\hline
\end{tabular}

\section{Table 3: Distribution of lesions according to artery involved}

\begin{tabular}{lcccc}
\hline Lesion & Left anterior descending artery & Right coronary artery & Let circumflex artery & Total \\
\hline Non atherosclerotic intimal thickening & 0 & 2 & 0 & 2 \\
Non atherosclerotic intimal xanthoma & 2 & 0 & 0 & 2 \\
Pathological intimal thickening & 0 & 0 & 2 & 2 \\
Fibrocalcific plaque & 30 & 18 & 10 & 0 \\
Fibrous cap atheroma & 11 & 4 & 0 & 15 \\
Plaque rupture & 2 & 0 & 2 & 4 \\
Calcified nodule & 0 & 26 & 14 & 85 \\
Total & 45 & & 2 & 0 \\
\hline
\end{tabular}

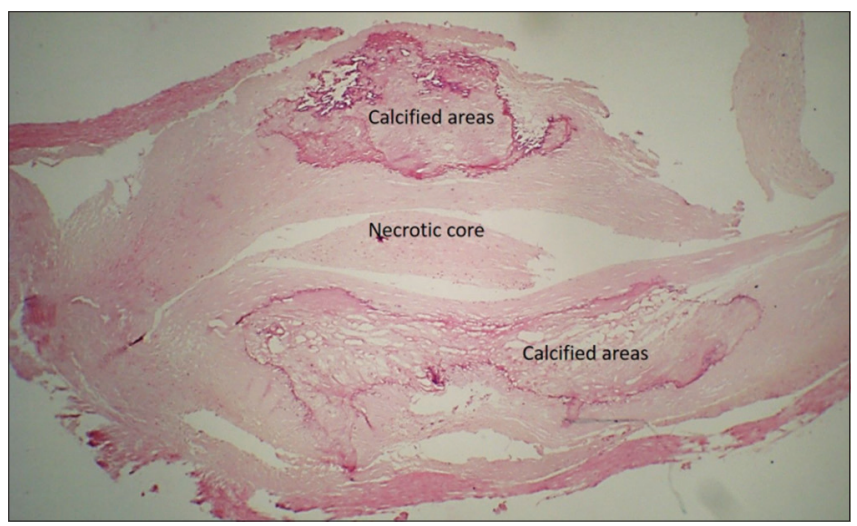

Figure 1 : Progressive atherosclerotic lesion - Fibrocalcific plaque - coronary artery displaying collagen rich plaque with necrotic core \& calcified areas; H\&E, 40x

\section{DISCUSSION}

Most of the atherosclerotic deaths occur in regions with high human development index. ${ }^{2}$ Our tertiary care centre also caters to population of Punjab, which is one of better developed states of the country. The patients suffering from CAD have premature onset of modifiable risk factors like dyslipidemia, smoking, hypertension, diabetes, high waist - hip ratio, unhealthy diet, low physical activity, irregular alcohol consumption and psychological stress. ${ }^{3,4}$ Recent trends indicate that not only has the age of onset of CVD come down, but the severity of CVD attacks and mortality associated with these events has also increased among Indians and South Asians. ${ }^{3,5}$ Gupta et al have demonstrated that the influence of the risk factors increases exponentially with age in Indians of 30-39 years of age and beyond. ${ }^{6}$ Moreover, some studies have shown that Indians and South Asians incur more severe and fatal attacks of CVD, resulting in greater morbidity and increased mortality.,

We found only two cases who were aged less than 40 years and they presented with fibrocalcific plaque. Porwal et al have reported atherosclerotic lesion even in a 15 years old patient. ${ }^{8}$ Puri et al found atherosclerotic changes in all cases above 25 years of age in their autopsy study on coronary atherosclerosis. One third of their cases displaying Grade IV atherosclerotic changes were less than 40 years of age. ${ }^{9}$ Golshahi et al reported the average age as 31.09 years in their autopsy study. ${ }^{10}$ Bhanvadia et al have reported that $37.1 \%$ of their cases were less than 40 years old and they had predominantly pathological intimal thickening, which is a precursor of advanced atherosclerosis. Advanced atherosclerotic lesions were common in older age group in their study. ${ }^{11}$ Virmani et al also observed that maximum cases were seen between fourth and fifth decades of life and advanced atherosclerotic lesions were predominant in this age group. ${ }^{12}$ In our study also, advanced atherosclerotic lesions were more commonly seen in older age groups, viz fifth to seventh decades of life (Table 1).Vyas et al,Dhruva et al and Garg et alhave found progressive increase in atherosclerosis from third decade onwards while Yazdi et al,Wig et aland Singh et al have reported significant increase in number as well as severity of atherosclerosis from second decade of life onwards. ${ }^{13-18}$ Marwah et al also found significant atherosclerosis in hearts of all cases more than 70 years of age, in their autopsy study on sudden cardiac deaths. ${ }^{19}$

In our study, male to female ratio was $4.3: 1$ with $76.5 \%$ males and $23.5 \%$ of cases being females. These findings 


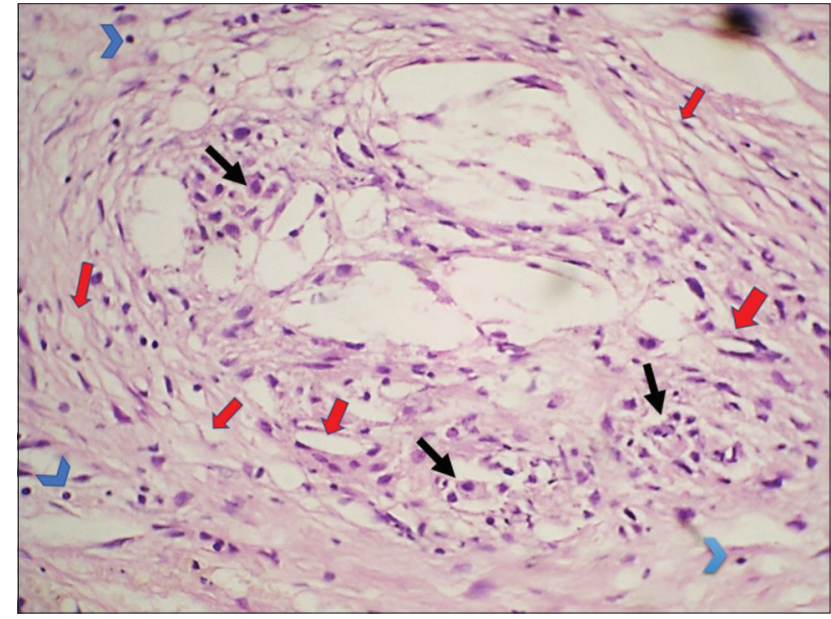

Figure 2 : Progressive atherosclerotic lesion -Fibrous cap atheroma -H\&E section showing coronary artery atheromatous plaque with central lipid core and periphery containing cholesterol clefts (red arrows), foam cells (black arrows) surrounded by lymphocytes (Blue arrowheads); 400x

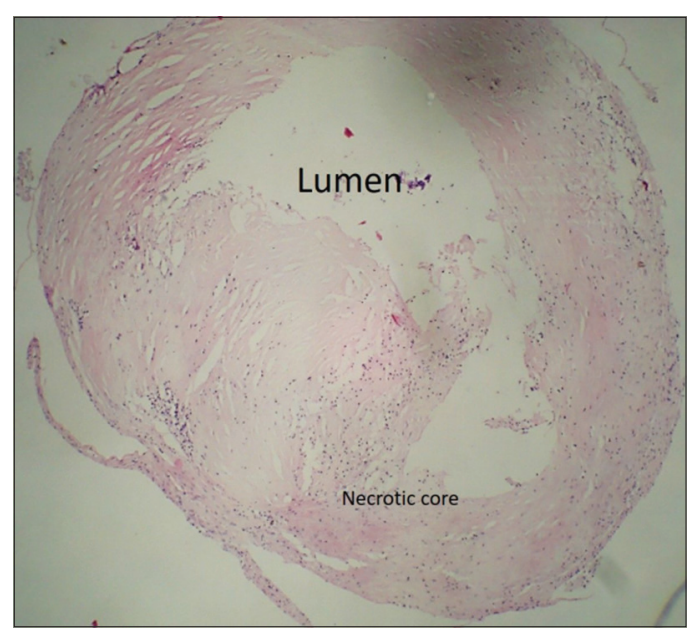

Figure 3 : Progressive atherosclerotic lesion-Plaque rupture - Coronary artery showing plaque rupture with communication between thrombus and underlying necrotic core; H\&E, 40x

are concordant with the findings of other studies on atherosclerotic lesions. Garg et al and Porwal et al found coronary atherosclerotic lesions in $80.9 \%$ and $74.75 \%$ males respectively, as compared to $19.1 \%$ and $25.24 \%$ females respectively. ${ }^{8,15}$ In study on coronary atherosclerosis by Singh et al, $85 \%$ cases were males while only $15 \%$ were females while in study by Vyas et al, $82 \%$ of the cases were males as compared to $18 \%$ females. ${ }^{13,18}$ Even Golshahi et al found that $88.5 \%$ of their cases were males as compared to $11.5 \%$ females. ${ }^{10}$ Male preponderance for atherosclerosis can be explained by protective effect of estrogen in females and greater incidence of smoking and alcoholism in males, which may predispose to advanced atherosclerosis. ${ }^{711}$

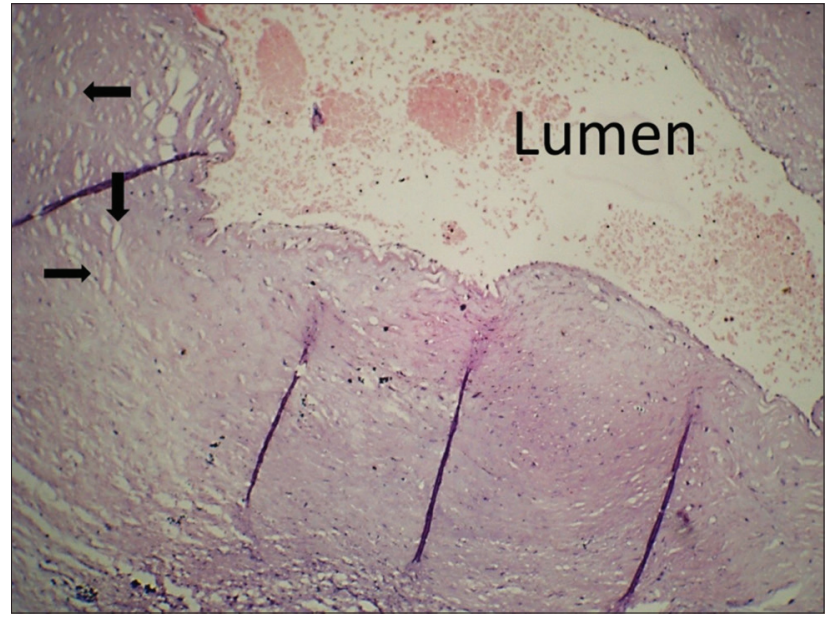

Figure 4 : Progressive atherosclerotic lesion -Pathological intimal thickening - Coronary artery displaying pathological intimal thickening with cholesterol clefts (black arrows), H\&E, 40x

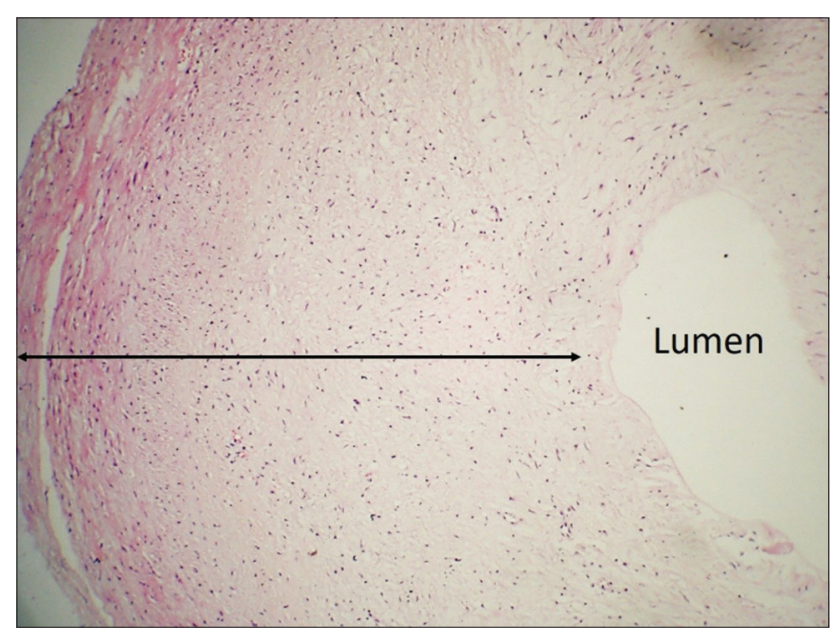

Figure 5: Photomicrograph of coronary artery showing Non atherosclerotic lesion - intimal thickening in absence of lipid or foam cells ; H\&E, $100 x$

In our study, left anterior descending artery (LAD) was the commonest site of involvement $(52.38 \%)$ as also reported by Golshahi et al (19.6\%), Porwal et al (46.6\%), Bhanvadia et al $(42 \%)$, Vyas et al $(40 \%)$, Yazdi et al $(60 \%)$, Garg et al (38.1\%) and Sudha et al (47\%). ${ }^{8,10,11,13,15,16,20}$ Marwah et al also found LAD as the commonest site for atherosclerotic lesions in their autopsy study of cases having sudden cardiac death. ${ }^{19}$ Ivanovic et al also found that two third of their studied plaques were situated in the LAD. LAD plaques were more commonly associated with high risk morphological features. ${ }^{21}$

We have reported findings of one vessel endarterectomy specimen which was found to be blocked by coronary plaque during coronary artery bypass grafting. Other authors have done autopsy based studies and have reported triple vessel and double vessel involvement. Porwal et al, Vyas et al, 
Dhruva et al and Garg et al have reported single vessel involvement in $15 \%, 13 \%, 31 \%$ and $13.3 \%$ of their cases respectively. ${ }^{8,13-15}$ All these authors, including Yazdi et al, have reported triple vessel involvement to be commoner than single vessel involvement. ${ }^{16 \mathrm{Mar}}$ wah et al also observed that out of 142 cases of coronary artery atherosclerosis in their study, $52 \%$ had triple vessel disease followed by single vessel disease in $26.4 \%$ and two vessel involvement was present in $21.6 \%{ }^{19}$ However, Puri et al and Virmani et al observed predominant single vessel involvement in their study. ${ }^{9,12}$

According to Modified American Heart Association classification of atherosclerosis, we had only two cases each of non - atherosclerotic intimal thickening, non - atherosclerotic intimal xanthoma and pathological intimal thickening. Most of our cases had advanced atherosclerotic lesions in the form of fibrocalcific plaques $(69.05 \%)$ followed by fibrous cap atheroma (16.67\%). Most of the autopsy studies have followed the morphological classification by American Heart Association for atherosclerosis. Porwal et al and Garg et al have reported maximum incidence of pre atheromas while Dhruva et al found more cases of fibroatheroma followed by preatheroma. ${ }^{8,14,15}$

According to Sudha M et al, cases of sudden cardiac deaths were found to have high grade coronary atherosclerotic lesions, majority comprising of vulnerable plaques which have extensive inflammation. ${ }^{20}$ Calcification stabilizes plaques and prevents rupture. ${ }^{22}$ Most of the disrupted plaques have necrotic lipid rich core, less smooth muscle cells and thin fibrous caps with foamy macrophages at the periphery. ${ }^{23}$ Acute coronary syndromes without ST elevation are also associated with plaques having necrotic core which are more unstable and likely to rupture. Patients should receive aggressive lipid defence therapy to stabilise plaques and thus reduce mortality and limit morbidity due to $\mathrm{CAD}^{21}$

\section{CONCLUSION}

We have hereby analysed themorphological spectrum of atherosclerotic lesions in live patients in a tertiary care institute of North western region. It is alarming to note that even patients less than 40 years old can harbour features of progressive atherosclerosis in coronary artery plaques at the time of presentation. We are actually sitting on a time bomb. To prevent morbidity and mortality due to CAD, aggressive lipid defence treatment and preventive measures in the form of awareness among the masses, policy changes, adoption of healthy lifestyle practices need to be implemented in the community at war footing.

\section{REFERENCES}

1. Registrar General of India. Sample Registration System Report. New Delhi, India: Office of the Registrar General. Available at: www.censusindia.gov.in/2011-common/sample_registration_ system.html; 2011. Accessed January 27, 2016.

2. Kuate - Defo B. Beyond the transition frameworks: the cross continuum of health, disease and mortality framework. Global Health Action 2014;7:1-16.

3. Joshi P, Islam S, Pais P, Reddy S, Dorairaj P, Kazmi K, et al. Risk factors for early myocardial infarction in South Asians compared with individuals in other countries. JAMA 2007; 297:286-294.

4. Global, regional, and national age - sex specific all - cause and cause - specific mortality for 240 causes of death, 1990 - 2013: a systematic analysis for the Global Burden of Disease Study 2013, GBD 2013 Mortality and Causes of Death Collaborators. Lancet 2015; 385:117-170.

5. Yusuf S, Rangarajan S, Teo K, Islam S, Li W, Liu L, et al. PURE Investigators. Cardiovascular risk and events in 17 low-, middle-, and high-income countries. N Engl J Med. 2014; 371:818-827.

6. Gupta R, Joshi P, Mohan V, Reddy KS and Yusuf S. Epidemiology and causation of coronary heart disease and stroke in India. Heart. 2008; 94:16-26.

7. Gupta R, Misra A, Vikram NK, Kondal D, Gupta SS, Agrawal A, et al. Younger age of escalation of cardiovascular risk factors in Asian Indian subjects. BMC Cardiovasc Disord. 2009;9:28.

8. Porwal V, Khandelwal S, Jain D and Gupta S. Histological classification of atherosclerosis and correlation with ischemic heart disease: a autopsy based study. Annals of Pathology and Laboratory Medicine 2016;3: A 100-104.

9. Puri N, Gupta PK, Sharma J and Puri D. Prevalence of atherosclerosis in coronary artery and internal thoracic artery and its correlation in North - West Indians. Indian J Thorac Cardiovasc surg 2010;26:243-246.

10. Golshahi J, Rojabi P and Golshahi F. Frequency of atherosclerotic lesions in coronary arteries of autopsy specimens in Isfahan forensic medicine center. J Res Med. 2005;1:16-19.

11. Bhanvadia VM, Desai NJ and Agarwal NM. Study of coronary atherosclerosis by Modified American Heart Association classification of atherosclerosis - An autopsy sudy. J Clinical Diagnostic Research 2013; 7:2494-2497.

12. Virmani R, Kolodgie FD, Burke AP, Farb A and Schwartz SM. Lessons from sudden coronary death - a comprehensive morphological classification scheme for atherosclerotic lesions. Arterioscler Thromb Vasc Biol 2000;20:1262-1275.

13. Vyas P, Gonsai RN, Meenakshi C and Nanavati M. Coronary atherosclerosis in non cardiac deaths: An autopsy study. J Midlife Health 2015;6:5-9.

14. Dhruva GA, Agravat $\mathrm{AH}$ and Sanghvi HK. Atherosclerosis of coronary arteries as predisposing factor in myocardial infarction: An autopsy study. [Last accessed on 2013 Dec 13]; Online J Health Allied Scs. 2012 11:1.

15. Garg M, Agarwal $A D$ and Kataria SP. Coronary atherosclerosis and myocardial infarction: An autopsy study. [Last accessed on 2013 Dec 13]; J Indian Acad Forensic Med 2011; 33:39-42.

16. Yazdi SA, Rezaei A, Azari JB, Hejazi A, Shakeri MT and Shahri MK. Prevalence of atherosclerotic plaques in autopsy cases with noncardiac death. Iran J Pathol 2009;4:101-104.

17. Wig KL, Malhotra RP, Chitkara NL and Gupta SP. Prevalence of coronary atherosclerosis in northern India. Br Med J 1962; 1:510-513.

18. Singh $\mathrm{H}$, Oberoi SS, Gorea RK and Bal MS. Atherosclerosis in coronaries in malwa region of Punjab. J Indian Acad Forensic 
Med 2005; 27:32-35.

19. Marwah N, Sethi B, Gupta S, Duhan A, Singh S and Sen R. Histomorphological spectrum of various cardiac changes in sudden death: an autopsy study. Iranian J Pathol 2011; 6:179-186.

20. Sudha ML, Sundaram S, Purushothaman KR, Kumar PS and Prathiba D. Coronary atherosclerosis in sudden cardiac death: An autopsy study. Indian J Pathol Microbiol 2009;52:486-489.

21. Ivanovic M, Rancic M, Rdzanek A, Filipjak KJ, Opolski G and Cvetanovic J. Virtual histology study of atherosclerotic plaque composition in patients with stable angina and acute coronary syndromes without ST segment elevation. Srp Arh Celok Lek 2013;141:308-314.

22. Moreno PR, Purushothaman KR, Fuster V and O'Connor WN. Intimomedial interface damage and adventitial inflammation is increased beneath disrupted atherosclerosis in the aorta: implications for plaque vulnerability. Circulation 2002;105:2504-2511.

23. Sano K, Kawasaki M, Ishihara $Y$, Okubo M, Tsuchiya K, Nishigaki K, et al. Assessment of vulnerable plaques causing acute coronary syndrome using integrated backscatter intravascular ultrasound. J Am Coll Cardiol 2006;47:734-741.

Author's contribution:

RKG and RT - Concept and design of the study, reviewed the literature, collected data, analysed data, prepared first draft of manuscript, performed statistical analysis, critically reviewed manuscript, manuscript editing; VS, SK, GS and SR - reviewed the literature, collected data, analysed data, critically reviewed manuscript; PKS and BG - analysed data, critically reviewed manuscript, manuscript editing.

\section{Orcid ID:}

Rajiv Kumar Gupta - (i) https://orcid.org/0000-0003-4319-9163

Ruchita Tyagi - (1) https://orcid.org/0000-0002-5404-5996

Vikrampal Singh - (D) https://orcid.org/0000-0001-5391-7152

Samir Kapoor - (iD https://orcid.org/0000-0002-7542-1876

Gurmeet Singh - io https://orcid.org/0000-0002-7209-0370

Sarju Ralhan - (1) https://orcid.org/0000-0003-4483-6574

Pavneet Kaur Selhi - (D) https://orcid.org/0000-0001-6964-6377

Bhavna Garg - (1) https://orcid.org/0000-0001-8637-2857

Harpreet Kaur - (1) https://orcid.org/0000-0002-0664-6107

Neena Sood - (1) https://orcid.org/0000-0001-8565-7914

Naved Aslam - (D) https://orcid.org/0000-0003-1163-8512

Gurpreet Singh Wander - (D) https://orcid.org/0000-0002-4596-4247

Source of Support: Nil, Conflict of Interest: None. 